\title{
Editorial
}

\section{Guillermo Restrepo}

Published online: 3 February 2013

(C) Springer Science+Business Media Dordrecht 2013

This special issue of Foundations of Chemistry collects five of the papers presented at the International Society for the Philosophy of Chemistry-Summer symposium 2011 (ISPC 2011), held in Latin America for the first time at the Universidad de los Andes (Bogota, Colombia). The symposium was sponsored by the Universidad de los Andes and organised by José L. Villaveces from the local university and Guillermo Restrepo from the Universidad de Pamplona (Colombia). The meeting took place 9-11 August 2011 and had 70 participants from 10 countries; 17 lectures were given, four of them by the following keyspeakers: Rom Harré (UK), Alan J. Rocke (USA), Eric Scerri (USA) and Joachim Schummer (Germany). History, philosophy, chemistry and pedagogy were the main topics of the lectures. The complete list of speakers and their abstracts and respective lectures are found in:

https://sites.google.com/site/intsocphilchem2011/home

The first paper, "Technochemistry, one of the chemists' ways of knowing”, by José A. Chamizo, approaches technochemistry following Pickstone's characterization of technoscience. Chamizo shows the importance of models and modelling in chemistry and their relationship with research and pedagogy.

"What did "Theory' mean to Nineteenth-century chemists?" is the title of the second paper, by Alan Rocke. There, the author argues against the claim that nineteenth-century chemistry lacked theoretical foundations. He states that this error is based upon a narrow conception of what a scientific theory is. By giving a broader sense to a scientific theory, not focused on physics, Rocke concludes that nineteenth-century chemistry benefited to a big extent from chemical theory.

Farzad Mahootian is the author of the third paper entitled "Paneth's epistemology of chemical elements in light of Kant's Opus Postumum". There, Mahootian shows that Paneth's reasons to differentiate between empirical and transcendental concepts of

G. Restrepo (ه)

Interdisciplinary Research Institute, Universidad de Pamplona, Bogotá, Colombia e-mail: guillermorestrepo@gmail.com; grestrepo@unipamplona.edu.co

G. Restrepo

Laboratorio de Química Teórica, Universidad de Pamplona, Pamplona, Colombia 
chemical element are rooted in Kantian philosophy, especially in the separation of regulative and constitutive principles.

The fourth paper, "To mathematize, or not to mathematize chemistry", by Guillermo Restrepo, discusses the relationship between mathematics and chemistry. By analysing different scholars' positions for and against mathematization of chemistry, the author concludes that it should not be discussion on the existence of mathematical chemistry, for it has existed since long time ago. Restrepo argues that mathematical chemistry is not using mathematics in chemistry but doing chemistry with mathematical mind, i.e. defining variables, symbolising and relating them through functions; to support his argument, Restrepo takes Kant and Comte positions on chemistry and mathematics.

"Molecules and mereology" is the title of the fifth paper, by Rom Harré and Jean-Pierre Llored. There, the authors ponder on the whole/parts relations of the particular case of molecules. They find some fallacies in chemical discourses and explore their chemical and philosophical consequences. Most of the paper deals with discourses based upon three ontological categories, i.e. molecule, atom and electron.

Lucía Lewowicz and Olimpia Lombardi are the authors of "Stuff versus individuals", a paper presented at the ISPC 2011 but already published online in this journal. The authors ponder on the ontology of chemistry and contrast it with the ontology of physics, the first one being of stuffs while the latter of individuals. The reason of this contrast is the widespread use of physics ontology to treat chemical questions. Lewowicz and Lombardi end up by finding that chemical ontology may help in understanding some issues of the philosophy of physics.

The ISPC 2011 also counted on the presentation of the book "Historia y filosofía de la química, aportes para la enseñanza", edited by José A. Chamizo, who took advantage of the presence of Olimpia Lombardi (who wrote a chapter of the book) to invite her to comment, along with him, on the aim of the book, namely writing a textbook in Spanish combining philosophy and history of chemistry for Latin American students.

Besides the academic programme, there were several other opportunities to enjoy the time, e.g. the lunches at the restaurants at the Universidad de los Andes and the tour along Bogota on a very traditional Colombian bus, a "chiva", which was properly modified to become a tourist bus with enough space to dance local music. The chiva took the participants to different places of Bogota, especially to "La Calera"; where there was time to enjoy local meals and spirits and to have a nice view of Bogota at night from a mountain over $2,700 \mathrm{~m}$ above the sea level.

The meeting, at the time of writing this editorial, has given place to its first fruits, namely the invitation of Joachim Schummer to attend a meeting on philosophy of chemistry and education in Brazil and the organization of the 3rd International Conference on the Periodic Table, held in Cusco (Peru) in 2012 and organised by some of the participants to the ISPC 2011.

I really hope this first ISPC Summer symposium organised in Latin America be the first one of many in the same continent! 